\title{
Maternal outcomes among emergency obstetric admissions at a tertiary care teaching hospital in Chitradurga, South India
}

\author{
Anju Arpana ${ }^{1 *}$, Rashmi B. M. ${ }^{2}$, Latha V. ${ }^{1}$
}

\begin{abstract}
${ }^{1}$ Department of Obstetrics and Gynecology, ${ }^{2}$ Department of Community Medicine, Basaveshwara Medical College and Hospital, Chitradurga, Karnataka, India
\end{abstract}

Received: 06 September 2018

Accepted: 05 October 2018

\section{*Correspondence:}

Dr. Anju Arpana,

E-mail: dr.anju.a@gmail.com

Copyright: () the author(s), publisher and licensee Medip Academy. This is an open-access article distributed under the terms of the Creative Commons Attribution Non-Commercial License, which permits unrestricted non-commercial use, distribution, and reproduction in any medium, provided the original work is properly cited.

\begin{abstract}
Background: The maternal mortality is a vital index of the quality and efficiency of obstetric services prevailing in a country. The obstetric emergencies are unexpected occurrences during pregnancy or puerperium requiring immediate attention. Obstetric emergencies can either happen suddenly or they can develop as a result of complications that are not properly identified, monitored or managed. These emergencies, to a large extent, are preventable. The purpose of this study was to understand the contributing factors of obstetric emergencies, their clinical presentation, management and maternal outcomes.

Methods: A cross sectional study was conducted among obstetric emergency admissions during October 2016 to September 2017, at a tertiary care hospital in urban area of central Karnataka.

Results: A total of 100 emergency admissions were observed in the study period. A $41 \%$ of were un-booked antenatal cases. A $13 \%$ of patients reached with the longest delay of 10-12 hours duration. A $31 \%$ of emergency admissions were in compromised condition. The majority of the cases were delivered by LSCS (55\%).

Conclusions: In the study, nearly half of the pregnancies were unbooked. There were teenage pregnancies reported in the study. More than half of obstetric emergencies were from rural areas. In nearly $50 \%$ of admissions a delay of more than 5 hours in reaching this hospital was noted. Ignorance was a major factor which impeded the access of antenatal health care services. Health education to pregnant women about importance of accessing maternal health services, early ANC booking and regular checkups, identification of high-risk pregnancy and timely referral, availability of fully functional first referral units and transport facilities for these emergency patients. Availability of skilled medical professionals round the clock in these FRU's are the need of the hour.
\end{abstract}

Keywords: Delay in seeking health care, Maternal morbidity, Maternal mortality, Obstetric emergencies, Obstetric referral

\section{INTRODUCTION}

Maternal mortality is a vital index of the quality and efficiency of obstetric service, prevailing in a country. One of the most important causes of maternal morbidity and mortality are obstetric emergencies that occur unexpectedly, either during pregnancy or puerperium, as a result of complications that are not properly identified, monitored or managed with timely and appropriate medical care, during the course of pregnancy. An emergency can be defined as a situation of serious and often dangerous nature, developing suddenly and unexpectedly and demanding immediate attention in order to save life. ${ }^{1}$ These emergencies are often lifethreatening and demand immediate specialized medical care. ${ }^{1-3}$ About $15 \%$ of all pregnant women may get a complication with an emergency during pregnancy, labour or puerperium. ${ }^{2,3}$ 
India is the second largest country in the world, next only to China, with a population of more than one billion. The existing demographic and socio-economic indicators of the country are showing that there is a scope for improvement. The main reasons for delay as per the delay model are delay in seeking treatment, delay in reaching health care facility, delay in identifying risk factors and delay in obtaining definitive treatment in the facility. ${ }^{4}$ The urban areas of the nation have well equipped and well-staffed maternity care institutions. Transport is also readily available so that these emergencies are timely attended with specialized care. However, higher percentage of the deliveries and obstetric emergencies are reported among women from rural areas, who belong commonly to lower socio-economic strata and often do not avail existing maternal health care services. ${ }^{5}$ The community health centres which are the first referral units (FRU), providing specialized medical care for obstetrical emergencies with the facilities of obstetricians and gynaecologists, paediatricians, surgeons and physicians. They are also equipped with full-fledged blood bank and para-medical services round the clock. Such FRUs have the capacity to anticipate these obstetric emergencies, detect them early and treat them adequately. But, the existing FRUs are deficient in infrastructure and manpower in many parts of India, which has been adversely affecting health of rural population. ${ }^{6}$ In rural areas, rapid transportation services are also scarce, because of which the time taken to reach a referral hospital / taluk or district hospital is longer. ${ }^{2}$ And even after reaching the health care facility, there can be a possibility of a further delay of 2-3 hours before the initiation of necessary interventions, due to lack of specialized medical care services. The World Health Organization (WHO) therefore recommends that, to reduce maternal morbidity and mortality, these obstetric complications or emergencies should be treated at a first referral level by doctors trained in emergency obstetric care and who can carry out essential obstetric functions. Such first referral levels should be ideally situated closer to the patients' residence. ${ }^{7}$

Women comprise an important section of society, whose health should be focused upon by various preventive, therapeutic, surgical interventions during their child bearing period as it can pose a threat to their lives. The present study was conducted among the emergency obstetric admissions in the tertiary care teaching hospital of Chitradurga, to understand the contributing factors of obstetric emergencies, their clinical presentation, management and maternal outcomes prevalent in this region of central Karnataka.

\section{METHODS}

This cross-sectional study was conducted in Department of Obstetrics and Gynaecology of Basaveshwara Medical College and Hospital, Chitradurga, from $1^{\text {st }}$ October 2016 to $30^{\text {th }}$ September 2017 , after obtaining ethical clearance from institutional ethics committee.

\section{Inclusion criteria}

- Pregnancies beyond 28 weeks of gestation, singleton or multiple pregnancies, pregnancies with obstetric emergencies in $1^{\text {st }}$ and $2^{\text {nd }}$ stage of labour (such as malpresentation, malpositions, deep transverse arrest, obstructed labour, cephalopelvic disproportion, antepartum haemorrhage, rupture uterus, eclampsia, etc) and pregnancies with $3^{\text {rd }}$ stage labour complications like post-partum haemorrhage (PPH), rupture uterus, genital injuries, etc.

- Pregnancies with medical complications like anemia, diabetes mellitus, infective hepatitis, hypertension, heart disease etc., pregnancies with surgical complications like appendicitis, hernia etc were also considered in the inclusion criteria.

- Obstetric emergency cases referred from periphery to this hospital were also a part of inclusion criteria.

\section{Exclusion criteria}

- Consisted of pregnant women brought in moribund state.

All the obstetric emergency admissions which fulfilled the study criteria during this study period were included in the study, after obtaining informed consent from either the patient or their attenders. A semi-structured questionnaire consisting of details regarding sociodemographic profile, the reasons for referral, parity, antenatal care in present pregnancy, clinical presentations, present obstetric complications, previous obstetric, medical and surgical history and last menstrual period to calculate the gestational age were recorded. General physical examination including the vital signs, detailed obstetric examination and other system examinations, mode of deliveries, nature of surgery performed, number of units blood transfused and maternal outcomes were documented.

\section{Statistical analysis}

The data was compiled in Microsoft excel spread sheet and analyzed using SPSS for windows version 16.0. All the characteristics are summarized descriptively. For continuous variables, the summary statistics of $\mathrm{N}$ and mean were used. For categorical data, the number and percentage were used in the data summarized.

\section{RESULTS}

A total of 100 emergency admissions were observed in the study period. The majority of obstetric emergencies were among the age groups of 21- 25 years (37\%) and 26-30 years (36\%). Most of the patients belonged to class II and III Socio-economic strata, according to modified BG Prasad classification (33\% and $39 \%$ respectively). ${ }^{8}$ The majority were from the rural area (58\%). A high percentage of the participants had studied up to primary 
or secondary school level (37\% and $34 \%$ respectively) (Table 1).

Table 1: Socio-demographic profile of the study population.

\begin{tabular}{|c|c|c|}
\hline Parameters & Groups & $\begin{array}{l}\text { Percentage } \\
(\mathbf{N}=\mathbf{1 0 0})\end{array}$ \\
\hline \multirow{5}{*}{$\begin{array}{l}\text { Age group } \\
\text { (years) }\end{array}$} & $16-20$ & 12 \\
\hline & $21-25$ & 37 \\
\hline & $26-30$ & 36 \\
\hline & $31-35$ & 13 \\
\hline & $36-40$ & 2 \\
\hline \multirow{5}{*}{$\begin{array}{l}\text { Socio-economic } \\
\text { status }\end{array}$} & Class I & 14 \\
\hline & Class II & 33 \\
\hline & Class III & 39 \\
\hline & Class IV & 13 \\
\hline & Class V & 1 \\
\hline \multirow{2}{*}{$\begin{array}{l}\text { Place of } \\
\text { residence }\end{array}$} & Urban & 42 \\
\hline & Rural & 58 \\
\hline \multirow{4}{*}{$\begin{array}{l}\text { Educational } \\
\text { status }\end{array}$} & $12^{\text {th }}$ and/ or above & 27 \\
\hline & Up to high school & 34 \\
\hline & Up to primary school & 37 \\
\hline & Illiterate & 2 \\
\hline Total & & 100 \\
\hline
\end{tabular}

A majority of the pregnant women were booked antenatal cases $(59 \%)$ whereas $41 \%$ were un-booked cases. A higher percentage $(66 \%)$ of these obstetric emergency admissions were referred from various other health care facilities whereas a $44 \%$ were direct admissions. Most of the referrals were from nursing homes and clinics (19\%), followed by district hospitals (15\%). A high percentage of $44 \%$ patients reached the hospital with a delay of 2-4 hours duration, followed by $32 \%$ of patients reaching the hospital with a delay of 5-10 hours duration. A $13 \%$ of patients reached with the longest delay of 10-12 hours duration. Ignorance $(39 \%)$ was leading cause of delay in seeking care (Figure 1). A $31 \%$ of emergency admissions were in compromised condition.

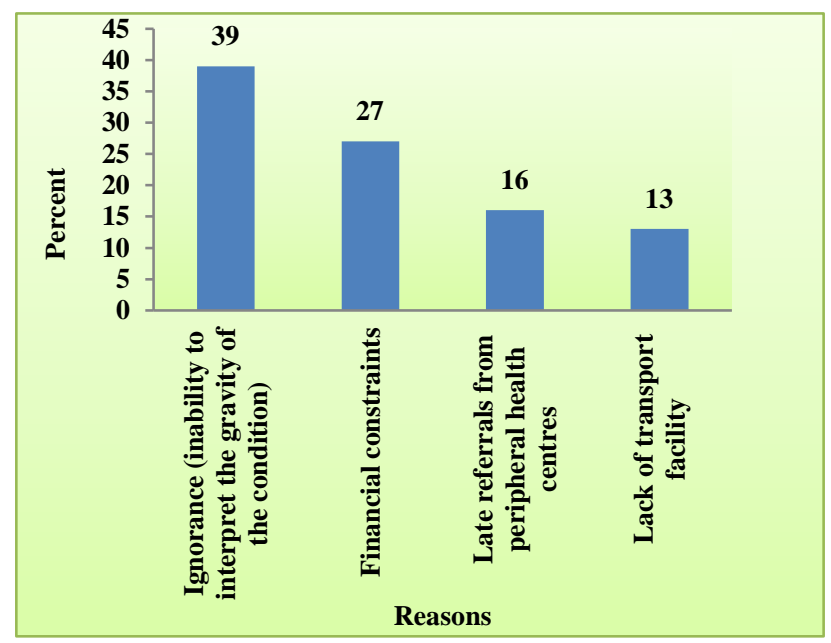

Figure 1: Reasons for delay in reaching the hospital $(\mathrm{N}=95)$.
Table 2: Mode of deliveries.

\begin{tabular}{|l|l|}
\hline $\begin{array}{l}\text { Mode of deliveries } \\
\text { Abdominal deliveries }\end{array}$ & $\begin{array}{l}\text { Percentage } \\
(\mathrm{N}=100)\end{array}$ \\
\hline $\begin{array}{l}\text { Emergency lower segment caesarean } \\
\text { section (LSCS) }\end{array}$ & 43 \\
\hline $\begin{array}{l}\text { Emergency LSCS with bilateral } \\
\text { tubectomy }\end{array}$ & 12 \\
\hline Laparotomy & 1 \\
\hline Total abdominal deliveries & 56 \\
\hline Vaginal deliveries & 6 \\
\hline \begin{tabular}{l} 
Instrumental \\
\hline $\begin{array}{l}\text { FTND with RMLE (full term normal } \\
\text { delivery right mediolateral episiotomy) }\end{array}$
\end{tabular} & 3 \\
\hline FTVD (full term vaginal delivery) & 17 \\
\hline Assisted breech delivery & 5 \\
\hline PTVD (pre-term vaginal delivery) & 13 \\
\hline Total vaginal deliveries & 44 \\
\hline Grand Total & 100 \\
\hline
\end{tabular}

The majority of the cases were delivered by Lower Segment Caesarean Section (LSCS-55 \%) followed by vaginal delivery (44\%) (Table 2). Most common indications for LSCS were malpresentations (23.6\%) followed by antepartum haemorrhage (16.4\%), fetal distress $(16.4 \%)$ and CPD (14.5\%). Of the $16.4 \%$ cases of antepartum haemorrhage, placenta previa was seen in $10.9 \%$ cases and abruption placentae in $5.5 \%$ cases. 2 of the 6 placenta previa cases had atonic PPH on table, which were managed by medical methods. Fetal distress was seen in $16.4 \%$ cases. Cephalopelvic disproportion in $14.5 \%$ cases and twin gestation in $10.9 \%$ of cases. Malposition was seen in $9.1 \%$ of cases, of which deep transverse arrest occurred in $7.3 \%$ of cases and Persistent occipito-posterior position was seen in 1 case (Table 3 ).

Table 3: Indications for LSCS.

\begin{tabular}{|ll|}
\hline Indications for LSCS & $\mathbf{N}=55(\%)$ \\
\hline Antepartum haemorrhage & $9(16.4 \%)$ \\
\hline Placenta previa & $6(10.9 \%)$ \\
\hline Abruptio placentae & $3(5.5 \%)$ \\
\hline Malpresentations & $13(23.6 \%)$ \\
\hline Breech & $11(20.0 \%)$ \\
\hline Shoulder & $1(1.8 \%)$ \\
\hline Cord presentation & $1(1.8 \%)$ \\
\hline Malposition & $5(9.1 \%)$ \\
\hline Occipito posterior persistent & $1(1.8 \%)$ \\
\hline Deep transverse arrest & $4(7.3 \%)$ \\
\hline Cephalopelvic disproportion & $8(14.5 \%)$ \\
\hline Imminent eclampsia & $4(7.3 \%)$ \\
\hline Eclampsia & $1(1.8 \%)$ \\
\hline Fetal distress & $9(16.4 \%)$ \\
\hline Twin pregnancy & $6(10.9 \%)$ \\
\hline Total & $55(100.0 \%)$ \\
\hline
\end{tabular}

In this study maternal morbidity was seen in $42 \%$ of cases. A high percentage of $17 \%$ patients received blood 
and blood component transfusion. Anaemia was present in $10 \%$ of cases and wound infection was present in $8 \%$ of cases, whereas there were no maternal mortalities (Figure 2).

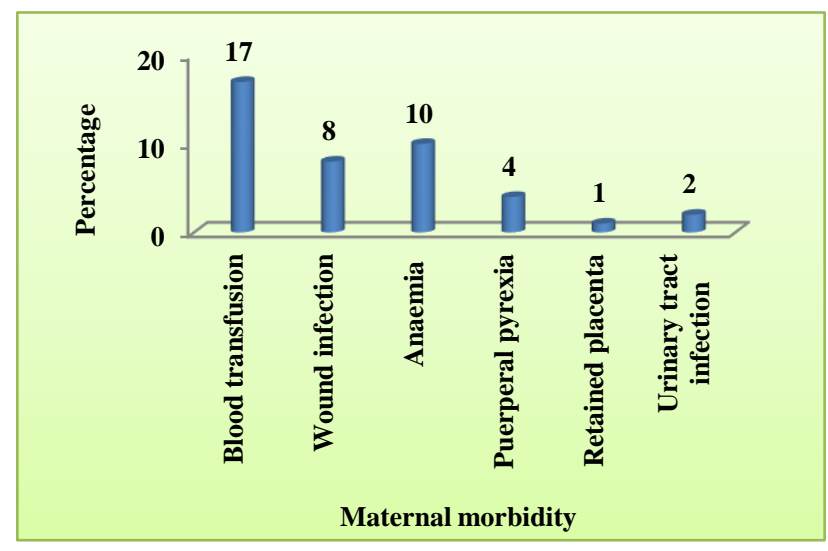

Figure 2: Maternal morbidity after admission.

\section{DISCUSSION}

The obstetric emergencies can happen suddenly, or they can develop as a result of a complication that are not properly managed or monitored. If an emergency is not properly treated, it may endanger the life or health of not only the mother but also her child. This study included a total of 100 obstetric emergency admissions and the obstetric outcomes were studied in relation to social and maternal factors.

In the present study, a majority (37\%) of obstetric emergencies were in the age groups of 21- 25 years whereas there also was a significant number of teenage pregnancies (16-20 years - in $12 \%$ of cases) (Table 1). The teenage pregnancies reflect the low socio-economic status and prevalent social custom in India which are also the causes for high fertility rates. ${ }^{9,10}$ Most of the emergency admissions in the present study were from rural areas $(58 \%)$, which might be due to the existent gross disparity between the availability and utilization of maternal health services between urban and rural areas. ${ }^{5,11-13}$ Unavailability of adequate medical facilities, either public or private, improper utilization of these facilities due to ignorance, socio-cultural barriers could have been the reasons for such higher obstetric emergencies occurring in rural areas. ${ }^{5,11-13}$ A majority of patients in the present study belonged to lower socioeconomic strata (Class III in $39 \%$, Class IV 13\%, Class $\mathrm{V}: 1 \%$ ) It has been observed that women of lower socio economic status often do not avail the existing maternal health services during pregnancy or at the time of delivery, which could have been the reasons for the emergency admissions. $5,11-13$

The obstetric emergencies were found to be more among primigravida (61\% cases-Table 4$)$. Similar results are found in the studies conducted by Goswamy P and Bindal J. ${ }^{14}$
Possible reasons for such high percentage of primigravidas coming to access care in obstetric emergency conditions could be due to lack of awareness regarding $\mathrm{MCH}$ care. A high percentage $(41 \%)$ of unbooked cases were also found in the present study which is more than the study done by Thaker $\mathrm{R}$ et al (Table 4). ${ }^{15}$

Table 4: Referral and obstetric details.

\begin{tabular}{|c|c|c|}
\hline Parameters & Characteristics & Percentage \\
\hline \multirow{2}{*}{$\begin{array}{l}\text { ANC care } \\
\text { status }\end{array}$} & Booked & 59 \\
\hline & Un-booked & 41 \\
\hline \multirow{3}{*}{$\begin{array}{l}\text { Referral } \\
\text { status }\end{array}$} & Referred & 66 \\
\hline & Not referred & 34 \\
\hline & Total & 100 \\
\hline \multirow{7}{*}{$\begin{array}{l}\text { Institution of } \\
\text { referral (out } \\
\text { of the total } \\
\text { referrals } \\
\mathrm{N}=66 \text { ) }\end{array}$} & District hospital & 15 \\
\hline & Taluk hospital & 9 \\
\hline & Community health center & 12 \\
\hline & Primary health center & 8 \\
\hline & Sub center & 3 \\
\hline & Nursing home and clinics & 19 \\
\hline & Total & 66 \\
\hline \multirow{6}{*}{$\begin{array}{l}\text { Delay in } \\
\text { reaching the } \\
\text { hospital }\end{array}$} & Time & Percentage \\
\hline & 0-1 hour & 5 \\
\hline & 1-2 hours & 6 \\
\hline & 2-4 hours & 44 \\
\hline & $5-10$ hours & 32 \\
\hline & 10-12 hours & 13 \\
\hline \multirow{3}{*}{$\begin{array}{l}\text { Obstetric } \\
\text { index }\end{array}$} & Primigravida & 61 \\
\hline & Multigravida & 36 \\
\hline & Grand multigravida & 3 \\
\hline \multirow{2}{*}{$\begin{array}{l}\text { Maternal } \\
\text { condition }\end{array}$} & Compromised & 31 \\
\hline & Good & 69 \\
\hline Total & & 100 \\
\hline
\end{tabular}

Out of 100 emergency admissions, a majority of $66 \%$ were referrals from various other health institutions. $34 \%$ of cases were not referred and had direct emergency admissions. Among them, 9\% were advised during antenatal checkup for hospital delivery. In most of the cases, the first access to health care was at PHC's, from there they were referred to higher centres (from nursing homes $19 \%$, from district hospitals 15\%), and when found unmanageable in those centres, they were further referred to this tertiary care teaching hospital (Table 4). The cases were referred due to non-availability of obstetrician, anaesthetist, paediatrician and also lack of facilities for caesarean section, lack of blood transfusion facilities and also lack of high dependency unit facilities to manage these obstetric emergencies in these institutions. $^{4,11}$

In majority of the emergency admissions, there was a delay in reaching this hospital by $2-4 \mathrm{hrs}$ ( $44 \%$ of cases), 5-10 hrs $(32 \%)$ and also $10-12$ hrs duration $(13 \%)$. The time taken could have been partly dependent on the mode of transportation and the distance of the place from the hospital and financial problem in patients. ${ }^{4}$ The precious 
golden period was being wasted and they were brought in advanced stages of labour, even several hours after rupture of membranes, in infected conditions and in state of threatened rupture of uterus or several hours after start of haemorrhage in a haemodynamically unstable condition. The ignorance $(32 \%)$ of the patients to seek medical aid was also an important factor for the delay in arriving the referral hospital (Table 4). Some of the referred cases failed to bring previous investigation reports and referral slips in hurry. The type I and type II delay affected the poor outcomes among mothers., ${ }^{2,4}$ Accompanying malnutrition and anaemia was also seen (compromised cases: $31 \%$, Table 4).

A $55 \%$ of pregnancies were delivered by lower segment caesarean section (Table 2). Similar results are found in the study conducted at Guntur by Guguloth $\mathrm{K}$ and Sivaranjani BSV. ${ }^{16}$ Malpresentations (23.6\%) and antepartum haemorrhage $(16.4 \%)$ were more common indications for LSCS observed in the present study (Table 3). Similar results are found in studies conducted elsewhere. ${ }^{16-19}$ This may be explained due to the fact that more number of cases were referred to this tertiary health centre from peripheral health care centres where operative facilities, blood transfusion facility and specialist care are unavailable.

The percentage of vaginal deliveries $(44 \%)$ was lesser in present study when compared with the findings of study conducted by Sabale U and Patankar AM, but similar to the study conducted by Bindal J.20,21 This was due to the fact that more number of cases were referred from outside where both mother and fetus were in a unsuitable condition go for normal or operative vaginal deliveries, hence the safest route to deliver was abdominal route by caesarean section which was opted for the management of obstetric emergencies (Table 3). LSCS for Imminent eclampsia was done in $4 \%$ of cases and for Eclampsia in one case. Baby was matured in this case, as a quick method of termination of pregnancy, LSCS was done.

Rupture uterus is one of the most serious obstetric emergencies associated with high maternal and fetal morbidity and mortality (Table 2). There was 1 case of rupture uterus out of 100 cases. The rupture was in unscarred uterus. It was a silent rupture i. e. there was no maternal and fetal distress. It was a complete rupture. The site of the rupture was in lower segment extending to lateral wall. Etiology for this rupture was labour acceleration with oxytocin. It was repaired by rent repair followed by tubectomy.

In this study maternal morbidity was seen in $42 \%$ cases (Figure 2). The morbidity was high because of preexisting anaemia, malnutrition and pre-existing infection at the time of admission and cross infections in the hospital. Blood transfusion was done to manage excessive haemorrhage in $17 \%$ of cases which is comparable with the study conducted by Poornima $\mathrm{M}$ and Daver R. ${ }^{22}$ In this study, emergency blood transfusion of
2-4 pints per patient was done to manage acute blood loss due to haemorrhage in placenta previa, abruptio placentae, post-partum cases. Blood components transfusion was done in maximum cases. Wound infection without pyrexia was the complication seen in $8 \%$ cases, even after being treated with higher antibiotics and in 2 cases antibiotics were changed as per culture report. Moderate anaemia was seen in $10 \%$ cases following delivery. It was managed with blood transfusion in 3\% cases and injectable iron followed by oral therapy in other $7 \%$ cases. Puerperal pyrexia was in $4 \%$ cases, managed by antibiotics and antipyretic. Retained placenta was seen in 1 case. Under general anesthesia (GA) manual removal of placenta was done. Urinary tract infection was observed in $2 \%$ cases, which was managed with antibiotics as per urine culture report.

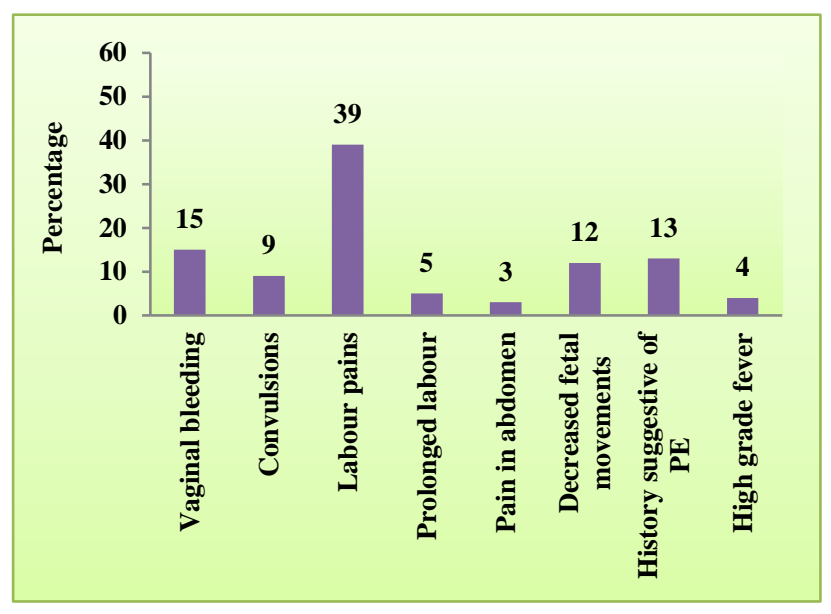

Figure 3: Details of clinical complaints on admission.

\section{CONCLUSION}

The obstetric emergency has a profound effect on the mother which can cause high maternal morbidity and mortality. One of the first and foremost goals of modern obstetrics is prevention of obstetric emergencies and to ensure that every pregnancy culminates in a healthy mother and a healthy baby. Though pregnancy is essentially a physiological process, unexpected complications may occur even in most healthy social environments. Efficient medical services are absolutely necessary to save lives. In the study, nearly half of the pregnancies were unbooked and belonged to middle/ lower socio-economic strata. There were teenage pregnancies reported in the study.

More than half of obstetric emergencies were from rural areas and nearly $50 \%$ of admissions reached the hospital with a delay of more than 5 hours duration. Ignorance was a major factor which impeded the access of antenatal health care services. Health education to pregnant women about maternal health services and its proper implication, Early ANC booking and regular checkups, identification of high-risk pregnancy and timely referral, fully functional first referral units, availability of transport 
facilities for these emergency patients, availability of obstetrician, anaesthetist, neonatologist, physician and surgeon services round the clock are the need of the hour.

\section{Funding: No funding sources}

Conflict of interest: None declared

Ethical approval: The study was approved by the Institutional Ethics Committee

\section{REFERENCES}

1. Campbell S, Lee C. Obstetric Emergencies. In: Obstetrics by Ten Teachers. Arnold Publishers; 2013:303-317.

2. Singh S, Doyle P, Campbell O, Rao G, Murthy G. Transport of pregnant women and obstetric emergencies in India: An analysis of the ' 108 ' ambulance service system data. BMC Pregn Childbirth. 2016;16:1-11.

3. Bang RA, Bang AT, Reddy MH, Deshmukh MD, Baitule SB, Filippi V. Maternal morbidity during labour and the puerperium in rural homes and the need for medical attention: A prospective observational study in Gadchiroli, India. BJOG. 2004;111:231-8.

4. Killewo J, Anwar I, Bashir I, Yunus M, Chakraborty J. Perceived Delay in Healthcare-seeking for episodes of serious illness and its implications for safe motherhood interventions in rural Bangladesh. J Health Popul Nutr. 2006;24(4):403-12.

5. Salam A, Siddiqui SA. Socioeconomic inequalities in use of delivery care services in India. J Obstet Gynecol India. 2006;56(2):123-7.

6. Pandve H, Giri P. First referral units (FRU): needs focus in Indian context. Int J Community Med Public Heal. 2015;2(2):75-6.

7. Bhatt R. Maternal mortality in india - FOGSI-WHO study. J Obstet Gynaecol India. 1997;207-14.

8. Singh T, Sharma S, Nagesh S. Socio-economic status scales updated for 2017. Int J Res Med Sci. 2017;5(7):3264-7.

9. Mahavarkar S, Madhu C, Mule V. A comparative study of teenage pregnancy. J Obstet Gynaecol (Lahore). 2008;28(6):604-7.

10. Rupakala BM, Shruthi AG, Nagarathnamma R. A study on teenage pregnancy and its maternal and fetal outcome. Int J Sci Res. 2016;5(5):2486-9.

11. Narwadkar M, Sakhare A, Mahale A. Critical study of referrals in obstetric emergencies. J Obstet Gynecol India. 2004;258-9.
12. Kaye D, Mirembe F, Aziga F, Namulema B. Maternal mortality and associated near-misses among emergency intrapartum obstetric referrals in Mulago hospital, Kampala, Uganda. East Africa Med J. 2003;80(3):144-9.

13. Irene YV, Vaneet K, Gurvinder K, Arun A, Lalita A. Critical care in obstetrics - scenario in a developing country. J Obstet Gynecol India. 2008;58(3):5-8.

14. Goswami P, Bindal J, Chug N. To study pattern of obstetric cases referred at tertiary care centre in Central India. Int $\mathbf{J}$ Reprod Contracept Obstet Gynecol. 2017;6(6):2370-4.

15. Thaker R, Deliwala K, Jadav M. Retrospective comparative study of obstetric complications and maternal mortality in registered and unregistered women at tertiary care hospital. NHL J Med Sci. 2013;2(1):28-35.

16. Guguloth K, Sivaranjani B. A retrospective study of maternal and perinatal outcome in obstetrical emergencies at government general hospital, Guntur. IOSR J Dent Med Sci. 2016;15(12):26-31.

17. Sharada M, Radhakrishnan J, Panigrahi P. Analysis of 100 cases of Obstetric Emergencies needing critical care in referral centres like steel plant hospitals. J Obstet Gynaecol India. 2001;51(6):8790.

18. Upadhyaya I, Chaudhary P. Severe acute maternal morbidity and intensive care in Paropakar maternity and women's hospital. Nep J Obs Gynaecol. 2013;8(2):38-41.

19. Saha R, Gautam P. Obstetric emergencies: fetomaternal outcome at a teaching hospital. NJOG. 2014;17(1):37-40.

20. Sabale U, Patankar A. Study of maternal and perinatal outcome in referred obstetric cases. J Evol Med Dent Sci. 2015;4(26):4448-55.

21. Bindal J, Sharma DC. Overview of referred obstetric patients and their outcome in tertiary care hospital. J Med Sci Clinic Res. 2017;5(5):22485-91.

22. Poornima M, Daver R. Maternal and fetal outcome in obstetric referred cases. Global J Res Analysis. 2018;7(2):544-7.

Cite this article as: Arpana A, Rashmi BM, Latha V. Maternal outcomes among emergency obstetric admissions at a tertiary care teaching hospital in Chitradurga, South India. Int J Reprod Contracept Obstet Gynecol 2018;7:4906-11. 